\title{
DEPRESSION AND ANXIETY POST TOTAL ABDOMINAL HYSTERECTOMY WITH BILATERAL SALPINGO- OOPHORECTOMY.
}

\author{
1. MBBS, FCPS (O \& G) \\ Senor Registrar Obstetrics and \\ Gynaecology \\ Isra University Hospital, Hyderabad, \\ Sindh, Pakistan. \\ 2. MBBS, MPhil (Pathology) \\ Lecturer \\ Department of Pathology \\ Liaquat University of Medical and \\ Health Sciences, Jamshoro, Sindh, \\ Pakistan. \\ 3. MBBS, FCPS (O \& G) \\ Assistant Professor Obstetrics and \\ Gynaecology, \\ Liaquat University Hospital \\ Jamshoro, Sindh, Pakistan \\ 4. MBBS, FCPS (Medicine) \\ Associate Professor Medicine \\ Isra University Hospital, Hyderabad, \\ Sindh, Pakistan. \\ Correspondence Address: \\ Dr. Sarosh Khan \\ Department of Obstetrics and \\ Gynaecology \\ Isra University Hospital, \\ Hala road, Hyderabad, Sindh, \\ Pakistan. \\ khan.sarosh07@gmail.com \\ Article received on: \\ $14 / 12 / 2018$ \\ Accepted for publication: \\ 29/03/2019
}

\section{INTRODUCTION}

Hysterectomy is one of the most common gynaecological procedures performed world over. Abdominal and vaginal routes both can be used to perform it. In the UK, among the major gynaecological surgeries, it remains the most common surgery performed. ${ }^{1}$

In the United States, among all the major surgical procedures, only appendectomy surpasses it. Prior to age 60, in the USA and UK, the frequency of women having hysterectomy is 1 out of 3 and 1 out of 5 women, respectively. However, the exact prevalence of hysterectomy is not known in Pakistan, it is believed to be the most commonly occurring surgical procedure, after Caesarian section, with a rate of $6.1-8.6 / 1000$ women of all ages. ${ }^{2,3}$
Fibroids, endometriosis, heavy bleeding, adenomyosis, prolapsed, advanced cervical and ovarian cancer are the conditions for which most of the hysterectomies are conducted. ${ }^{4}$

In women below 50 years age, prophylactic bilateral oophorectomy is performed along with hysterectomies in forty per cent cases, whereas in $1 / 3^{\text {rd }}$ of patients, despite preserving ovaries, ovarian failure develops. ${ }^{5}$

The procedure is associated with considerable morbidity, with the development of morbidity in a quarter of half of all the women who undergo hysterectomy, haemorrhage and fever being the most common. ${ }^{6}$ The residual ovary syndrome, increase the risk of cardiovascular disease and the psychological problems, the most frequently reported being anxiety and depression are 
included in late sequelae. ${ }^{7,8}$

Deciding on whether to undergo hysterectomy can be the most difficult and emotional decision of the couple. ${ }^{9}$ Women consider uterus as a centre of their womanhood and a symbolic organ, therefore, it's traumatic to have a hysterectomy. Considerable physical and psychological stress is experienced by women who undergo hysterectomy. ${ }^{10}$

In perimenopausal age, the procedure of hysterectomy is commonly carried out but may cause premature ovarian failure. The major effect on mood is linked to it due to the exhaustion of endogenous androgens which result as a consequence of associated bilateral oophorectomy. ${ }^{11,12}$

Women feel emotionally vulnerable post hysterectomy. ${ }^{4}$ Image of the body gets impaired as a result of scarring following surgery and losing uterus. ${ }^{13}$ The ability of a female to bear children is considered to be of a great significance in developing countries like Pakistan. Self-worth gets in jeopardy in the patients who undergo hysterectomy as they have to come to certain terms due to their incapability to bear children. ${ }^{14}$ Other features that cause emotional distress include the feeling of a breach of feminity, fear of menopause and ageing. ${ }^{15}$

Psychological consequences posthysterectomies include depression (8\%) and anxiety (6\%). ${ }^{10}$ Post hysterectomy, the most frequent psychiatric risks mentioned is depression. (13) Prolong and severe feelings of hopelessness and sadness, diminished interest in activities, insomnia, significant weight loss or gain; fatigue and thoughts of death or suicide are the signs of depression. ${ }^{4}$

It is being reported that up to $70 \%$ of the women who undergo hysterectomy with bilateral salpingooophorectomy experience sexual dysfunction to some extent in terms of loss of libido (up to $70 \%)$, difficulty in getting aroused up to (62\%) and vaginal dryness leading to dyspareunia (up to $46 \%) .{ }^{14,16,17}$ Sexual function has an impact on the quality of life in the women who go through a hysterectomy. It is considered an essential part of a good quality of life to have sexual satisfaction. Few women consider themselves unattractive if they don't have a uterus anymore which results in a bad body image. Women with a negative body image report less sexual satisfaction. ${ }^{18}$

A study was conducted at Lahore, Pakistan in which depression and anxiety were assumed in women undergoing hysterectomy before and after surgery. It was found that pre hysterectomy mean \pm SD depression score of $10.44 \pm 4.31$ increased to $12.48 \pm 3.71$ after surgery. Same way, pre hysterectomy mean $\pm S D$ anxiety score of $13.38 \pm 10.86$ increased to $27.10 \pm 13$ after the surgery. ${ }^{14}$

Another study which was done in Nigeria, it was observed that there was a rise of about $6.8 \%$ in disorders related to anxiety after hysterectomy, where patients with the clinical diagnosis of uterine fibroid had the greatest. ${ }^{19}$

In another study which was done in Egypt, it was observed that depression and anxiety symptoms were more common among nulliparas. ${ }^{20}$ Another study done in Japan concluded that in women who were afflicted by clinical depression, an incidence of hysterectomy and oophorectomy was greater. $^{21}$

This study has been attempted to determine the frequency and severity of depression and anxiety in patients who had undergone total abdominal hysterectomy with bilateral salpingo oophorectomy.

\section{MATERIAL AND METHOD}

A cross-sectional study was carried out at the Department of Obstetrics and Gynecology, Isra University Hospital, Hyderabad, Sindh from 14th January 2015 to $14^{\text {th }}$ January 2016.

Sample size calculation was done by taking the desired width of $95 \%$ confidence interval as $4 \%$ with the proportion of $6 \%^{5}$, the sample size was calculated as 136 cases with non-probability, purposive sampling technique. Women between the ages of 30 - 50 years, presented at the 
outpatient department three months after having undergone total abdominal hysterectomy with bilateral salpingo - oophorectomy were included in the study.

Exclusion Criteria included women who had undergone the Obstetrical hysterectomy which is a life-saving procedure, a vaginal hysterectomy that is mostly done in women above 50 years with prolapsed, Subtotal hysterectomy which is rarely done nowadays, hysterectomized women with pre-existing depression and psychosis and taking antidepressants and antipsychotic medications. And women who do not agree to participate in the study.

Data were collected after taking the informed consent by women attending the Isra University Hospital outpatient department, fulfilling the inclusion criteria. Exclusion criteria were strictly followed to control the confounding variables.

Anxiety and depression were labelled along with severity as per operational definition using the Zung self-rating anxiety scale and Zung selfrating depression scale.

The scoring system included 20 items with a layout of four-point Likert response $(1=$ a little of time, $4=$ most of time) on each of the 2 scales. Both scales contain positive as well as negative statements. ${ }^{10}$

Data were analyzed using SPSS version 11.0. Frequency and percentages were computed for qualitative variables like age, educational status, parity, anxiety, depression, and their severity level and Chi-square test was applied to determine the significance of these variables.

Mean \pm SD were computed for quantitative variables i.e. age, depression and anxiety scores. Stratification was done with regards to age, parity and education level. P-value $\leq 0.05$ was taken as significant. The research was conducted accordingly to the principles of the declaration. of total abdominal hysterectomy with bilateral salpingo-oophorectomy were selected for this study as per selection criteria. The age of these women was between 30-years and 50-years with a mean $\pm S D$ age of $42.29 \pm 5.53$-years.

The majority (29.4\%) of the cases were of more than 40-years in age. There was a highly significant association of age with anxiety $(P=0.004)$ as well as with depression $(\mathrm{P}<0.001)$. (Table-I)

The majority (66.9\%) of our study population was illiterate whereas only $2(1.5 \%)$ subjects were intermediate. Level of education had a highly significant association with anxiety $(P<0.001)$ and depression $(P<0.001)$. (Table-I)

Among the women selected for the study, most of them (88.2\%) were married.

Marital status was also highly significant associated factor with anxiety $(P=0.016)$. However, no significant association was found statistically between marital status and depression $(P=0.255)$. (Table-I)

The mean \pm SD parity of these women was $4.21 \pm 2.59$; the majority $(46.3 \%)$ of them were grand multiparous. A very highly significant association was found between parity and anxiety $(P<0.001)$ as well as between parity and depression $(P=0.002)$. (Table-I)

The mean $\pm S D$ score of all subjects on the Zung

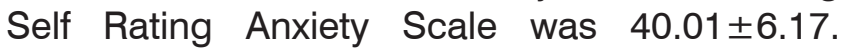
Anxiety was found to be present in 37 (27.2\%) subjects (Figure-1). All these 37 subjects had a mild-moderate level of anxiety (Figure-2).

The mean \pm SD score of all subjects on the Zung Self Rating Depression Scale was 41.73 \pm 11.15 . Depression was found to be present in 44 (32.4\%) subjects (Figure-1). Among these 44 subjects, 41 (30.1\%) had mild-moderate, whereas the remaining $3(2.2 \%)$ had a severe level of depression (Figure-2).

\section{RESULTS}

As per the calculated sample size, 136 cases 


\begin{tabular}{|c|c|c|c|c|c|}
\hline $\begin{array}{l}\text { Sr. } \\
\text { No }\end{array}$ & Variables & Percentage & Mean \pm SD & $\begin{array}{c}\text { Association with } \\
\text { Anxiety }\end{array}$ & $\begin{array}{l}\text { Association with } \\
\text { Depression }\end{array}$ \\
\hline 1 & AGE & & \multirow{5}{*}{$42.29 \pm 5.53$} & \multirow{5}{*}{$P=0.004$} & \multirow{5}{*}{$P<0.001$} \\
\hline & $30-35$ years & $17.6 \%$ & & & \\
\hline & $36-40$ years & $27.9 \%$ & & & \\
\hline & $41-45$ years & $25.0 \%$ & & & \\
\hline & $>45$ years & $29.4 \%$ & & & \\
\hline \multirow[t]{5}{*}{2} & EDUCATION & & & \multirow{5}{*}{$P<0.001$} & \multirow{5}{*}{$P<0.001$} \\
\hline & Illiterate & $66.9 \%$ & & & \\
\hline & Matriculation & $17.6 \%$ & & & \\
\hline & Intermediate & $1.5 \%$ & & & \\
\hline & Graduation & $14.0 \%$ & & & \\
\hline \multirow[t]{4}{*}{3} & MARITAL STATUS & & & \multirow{4}{*}{$P=0.016$} & \multirow{4}{*}{$P=0.255$} \\
\hline & Unmarried & $1.5 \%$ & & & \\
\hline & Married & $88.2 \%$ & & & \\
\hline & Widow & $10.3 \%$ & & & \\
\hline \multirow[t]{5}{*}{4} & PARITY & & \multirow{5}{*}{$4.21 \pm 2.59$} & \multirow{5}{*}{$P<0.001$} & \multirow{5}{*}{$P=0.002$} \\
\hline & Nulliparous & $8.1 \%$ & & & \\
\hline & Primiparous & $11.8 \%$ & & & \\
\hline & Multiparous & $33.8 \%$ & & & \\
\hline & Grandmultiparous & $46.3 \%$ & & & \\
\hline
\end{tabular}

Table-I. Demographic data and association with anxiety and depression

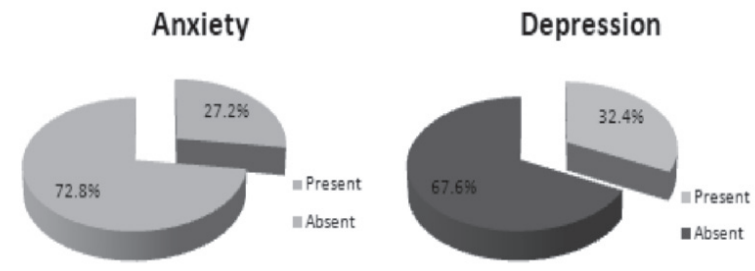

Figure-1. Anxiety and depression in patients post total abdominal hysterectomy with bilateral salpingooophorectomy

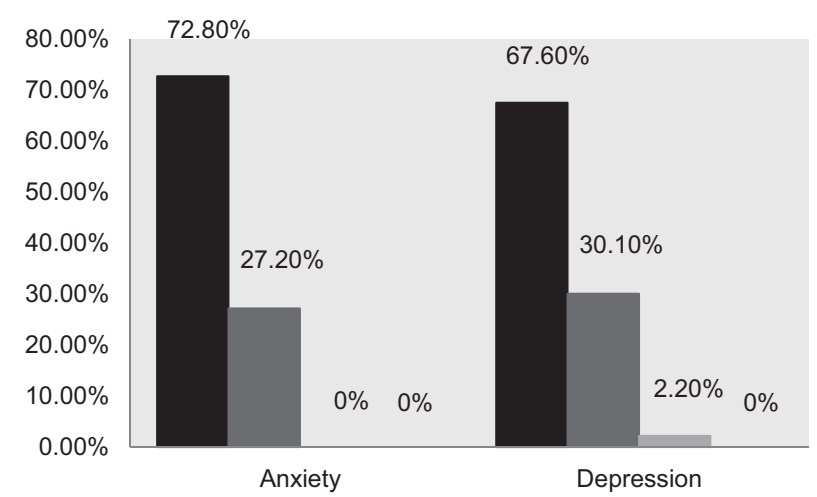

No Mild-Moderate Severe Extremely severe

Figure-2. Severity of anxiety and depression in patients post total abdominal hysterectomy with bilateral salpingo-oophorectomy

\section{DISCUSSION}

It has been all the time more acknowledged that various aspect of women's health can get affected by the hysterectomy procedure. Long-term consequences for a woman who is considering hysterectomy include effects on health-related quality of life, including sexual dysfunction and mental health. Quality of life has increasingly become an important priority and outcome variable in medical practice, a multidimensional concept which refers to an individual's wellbeing.

Various issues trouble women who have gone through hysterectomy apart from the loss of fertility, such as changes in body image, their relationship with their husband, effects of menopause and physical energy loss. ${ }^{22}$ It is also reported in the literature that there is an association between the way women perceive about this procedure and the psychological reaction which develops after hysterectomy. ${ }^{23}$

Post-hysterectomy, the psychiatric, physical and cultural aspects of psychiatric reactions should 
be considered, because despite its advantages and benefits, yet for many women, it is the loss of sexuality and femininity, loss of fertility, loss of importance in the eyes of the husband and his family. ${ }^{24}$

Post hysterectomy, the most commonly reported symptoms are depression and anxiety. ${ }^{25}$ Hysterectomy is seen as to be "loosing of fertility function" and development of infertility following the procedure, therefore, it is one of the major causes of anxiety and depression. Change of body image, the decrease in sexual interest, fear of losing sexual attractiveness, loss of sexual identity, fear of negative attitude of husband and/or his family, wish to bear a child, are the problems which usually lead to depression and anxiety after hysterectomy. ${ }^{26,27}$

In the present study, the severity of prevention and anxiety was determined along with frequency in patients who go through a total abdominal hysterectomy with bilateral salpingooophorectomy (TAH-BSO). The occurrence and severity of depression and anxiety were determined by means of using the questionnaires called Zung Self Rating Depression Scale (ZSDS) and Self Rating Anxiety Scale (ZSAS).

The Zung depression rating scale (ZSDS) and ZUNG anxiety rating scale are widely used and are well recognized 20 -item questionnaire which records self-reported responses based upon a 4-point Likert metric system which measures the tendency of depression and anxiety. It constitutes a total of 20 items related to affective, psychological, and somatic symptoms of depression. Responses of the inquired subject are reported on the fourpoint Likert type scale regarding the frequency of each symptom experienced, where the lowest score being 20 and highest $80 .^{28,29}$

Hysterectomy is usually performed in premenopausal or postmenopausal age. However for the present study subjects were selected between the ages of 30 years and 50 years, Majority of the subjects were of more than 40 years of age. Similar observations have been reported by Bashir $\mathrm{R}$ and colleagues in their study conducted at Ayub Teaching Hospital, Abbottabad-Pakistan ${ }^{30}$, and by Khaskheri $\mathrm{M}$ and Baloch's in their study conducted at Liaquat University Hospital, Jamshoro-Pakistan. ${ }^{31}$ A Nigerian study conducted by Okunlola MA and coworkers also reported similar results. ${ }^{19}$ Wang $X Q$ has also reported that the majority of the subjects in their study were in the age group of 41-50 years but their observed proportion is much higher than the present study. ${ }^{10}$ However, the age range in their study was from 20 years and above, which seems to be the reason for the difference in proportions.

Literacy plays an essential role in mental discovers. In the present study, the majority of the population was illiterate. A study conducted by Farooqui YN at lady Willington Hospital, Lahore, Pakistan ${ }^{14}$ reported almost identical observation as well as the Nigerian study. ${ }^{19}$ However, a Chinese study has reported that only about onethird of the study population was educated below junior high school. ${ }^{10}$ The literacy rate and socioeconomical status of a country is the prime cause of this difference.

In the present study, a large fraction of the women undergone hysterectomy was married, Wang $X Q$ and associates reported the even larger proportion of the women to be observed as married in their study conducted in China ${ }^{10}$ and almost identical proportion to their study was reported by Okunlola MA and colleagues. ${ }^{19}$ Others reported that all of the women undergone hysterectomy were married or to be married. ${ }^{14,32}$

In the present study, less number was nulliparous/ primiparous. About $80 \%$ of women in the present study were multiparous and grand multiparous. These observations are concurrent with those reported by Farooqui YN. ${ }^{14}$ However, Dawood NS and associates reported lower mean \pm SD parity than the present study. In their study conducted at Fauji Foundation Hospital, Rawalpindi, Pakistan ${ }^{32}$, which may be due to the fact that their study was conducted among urban population whereas the present study was at a hospital where a majority of the population belongs to rural setup. 
In the present study among the women undergone hysterectomy, anxiety was present in $27.2 \%$, however, all of these presented with a mild-moderate level of anxiety. A study, in which similar tools were used, reported that only $1.9 \%$ of subjects had a mild to moderate level of anxiety. ${ }^{10}$ In contrast, Farooqi YN has reported that severe anxiety was present among women undergone hysterectomy. ${ }^{14}$ However, this author used a different tool and collected data in the early post hysterectomy period.

In the present study, depression was present in $32.4 \%$ of subjects among which only $2.2 \%$ presented with severe depression. An American study reported almost identical results i.e. 33\% of the study subjects presented with depression. ${ }^{12}$ However, WANG XQ and coworkers reported only $4.8 \%$ subjects presented with depression, all at a mild level. ${ }^{10}$ In contrast to that Farooqi YN has reported that depression was found at a severe level in women undergone hysterectomy. ${ }^{14}$ Again the probable causes could be the difference of tools and post-hysterectomy data collection period.

The study has certain strengths that need to be acknowledged in the interpretation of the results. The topic of research was interesting and the findings could be beneficial to a larger extent for the individuals, families and society. Women's psychological status is very much ignored in our part of the world. By doing this study, we were able to assess how women felt about themselves after this surgery. Majority of the women fully understood the importance of this study and fully participated.

There are certain limitations to this studies that need to be acknowledged in the interpretation of the results. Pre-operative mental status was not known. In addition to the variables like marital status, parity, age that were considered in this study, there are certain other important risk factors like socio-economic status, domestic environment. Due to logistic limitations these important risk factors could not be addressed in this study.

\section{CONCLUSION}

It is concluded from this study that there was a highly significant association of age, parity, and level of education with anxiety as well as depression. Marital status was also significantly associated with anxiety, however, no association was found between marital status and depression. Majority of the women suffered from a mildmoderate level of anxiety and none suffered from severe anxiety. Majority of the women suffered from a mild-moderate level of depression, however, severe level of depression was also observed.

\section{ACKNOWLEDGEMENT}

We would like to thank Prof. Aftab A Munir and Prof. Nishat Zohra for their guidance throughout the study.

Copyright@ 29 Mar, 2019.

\section{REFERENCES}

1. Pradhanang V, Tuladhar H, Maskey S, Dali SM, Pradhan I. Review of hysterectomies at NMCTH-A retrospective study. Journal of Nepal health research council. 2005; 3(1):34-8.

2. Ahmed F, Wasti S. Infectious complications following abdominal hysterectomy in Karachi, Pakistan. International Journal of Gynecology \& Obstetrics. 2001 Apr $1 ; 73(1): 27-34$.

3. Nausheen F, lqbal J, Bhatti FA, Khan AT, Sheikh S. Hysterectomy: The patients perspective. Annals of King Edward Medical University. 2004; 10(4):339-41.

4. Vomvolaki E, Kalmantis K, Kioses E, Antsaklis A. The effect of hysterectomy on sexuality and psychological changes. The European Journal of Contraception \& Reproductive Health Care. 2006 Jan 1; 11(1):23-7.

5. McPherson K, Herbert A, Judge A, Clarke A, Bridgman $S$, Maresh M, Overton C. Psychosexual health 5 years after hysterectomy: population $\square$ based comparison with endometrial ablation for dysfunctional uterine bleeding. Health Expectations. 2005 Sep; 8(3):234-43.

6. Ahsan $S$, Naeem $S$, Ahsan A. A case notes analysis of hysterectomy performed for non-neoplastic indications at Liaquat National Hospital, Karachi. Journal-Pakistan Medical Association. 2001 Oct; 51(10):346-8. 
7. Siddle N, Sarrel $P$, Whitehead $M$. The effect of hysterectomy on the age at ovarian failure: identification of a subgroup of women with premature loss of ovarian function and literature review. Fertility and sterility. 1987 Jan 1; 47(1):94-100.

8. Bryan MM. Hysterectomy, social and psychosexual aspect. Baillieres. Clin. Obstet. Gynecol. 1997; 11:23-6.

9. Uskul AK, Ahmad F, Leyland NA, Stewart DE. Women's hysterectomy experiences and decision-making. Women \& health. 2003 Sep 17; 38(1):53-67.

10. Wang XQ, Lambert CE, Lambert VA. Anxiety, depression and coping strategies in post-hysterectomy Chinese women prior to discharge. International Nursing Review. 2007 Sep; 54(3):271-9.

11. Khastgir G, Studd J. Hysterectomy, ovarian failure, and depression. Menopause (New York, NY). 1998; 5(2):113-22.

12. Rohl J, Kjerulff K, Langenberg P, Steege J. Bilateral oophorectomy and depressive symptoms 12 months after hysterectomy. American journal of obstetrics and gynecology. 2008 Jul 1; 199(1):22-e1.

13. Yen JY, Chen YH, Long CY, Chang Y, Yen CF, Chen CC, $\mathrm{Ko} \mathrm{CH}$. Risk factors for major depressive disorder and the psychological impact of hysterectomy: $A$ prospective investigation. Psychosomatics. 2008 Mar $1 ; 49(2): 137-42$.

14. Farooqi YN. Depression and anxiety in patients undergoing hysterectomy. Journal of Pakistan Psych Society. 2005 Jan; 2:13-6.

15. Aziz A, Bergquist C, Brännström M, Nordholm L, Silfverstolpe $\mathrm{G}$. Differences in aspects of personality and sexuality between perimenopausal women making different choices regarding prophylactic oophorectomy at elective hysterectomy. Acta obstetricia et gynecologica Scandinavica. 2005 Jan 1; 84(9):854-9.

16. Ewalds-Kvist SB, Hirvonen T, Kvist M, Lertola K, Niemelä $P$. Depression, anxiety, hostility and hysterectomy. Journal of Psychosomatic Obstetrics \& Gynecology. 2005 Sep 1; 26(3):193-204.

17. Brandsborg B, Nikolajsen L, Kehlet $H$, Jensen TS. Chronic pain after hysterectomy. Acta Anaesthesiologica Scandinavica. 2008 Mar; 52(3):32731.

18. Sung $\mathrm{MH}$, Lim YM. Factors affecting sexual satisfaction in Korean women who have undergone a hysterectomy. Australian Journal of Advanced Nursing, The. 2009 Dec; 27(2):46.
19. Okunlola MA, Umuerri C, Omigbodun OO, MorhasonBello IO, Okonkwo SN, Ojengbede OA. Pattern of mental ill health morbidities following hysterectomy for benign gynaecological disorders among Nigerian women. International journal of mental health systems. 2009 Dec; 3(1):18.

20. Helmy YA, Hassanin IM, Elraheem TA, Bedaiwy AA, Peterson RS, Bedaiwy MA. Psychiatric morbidity following hysterectomy in Egypt. International Journal of Gynecology \& Obstetrics. 2008 Jul 1; 102(1):60-4.

21. Mantani A, Yamashita H, Fujikawa T, Yamawaki S. Higher incidence of hysterectomy and oophorectomy in women suffering from clinical depression: Retrospective chart review. Psychiatry and clinical neurosciences. 2010 Feb; 64(1):95-8.

22. Cimon R. The impact of hysterectomy and myomectomy on female sexual function and health related quality of life. [Thesis] Mersin Univeristy Medical School Department of Obstetrics and Gynecology, Medical Specialization Thesis, Mersin (2007).

23. Youngkin EQ, Davis MS, Schadewald DM, Juve C, editors. Women's health: A primary care clinical guide. Pearson/Prentice Hall; 2004.

24. Meston CM, Bradford A. A brief review of the factors influencing sexuality after hysterectomy. Sexual and relationship therapy. 2004 Feb 1; 19(1):5-14.

25. Fogel Cl, Woods NF. Women's sexuality. Women's Health Care in Advanced Practice Nursing, 1nd ed. New York: Springer Publishing Company. 2008:295-1.

26. Flory N, Bissonnette F, Binik YM. Psychosocial effects of hysterectomy: Literature review. Journal of psychosomatic research. 2005 Sep 1; 59(3):117-29.

27. Kantar B, Sevil U. Histerektomi ameliyatı olmus kadınlarda depresyon ve umutsuzluk düzeylerinin incelenmesi (Examination of women's level of depression and hopelessness after hysterectomy). Jinekoloji ve Obstetrik Dergisi. 2004; 18(1):17-24.

28. Zung WW. A self-rating depression scale. Arch Gen Psychiat.1965; 12:63-70.

29. Veletza S, Samakouri M, Emmanouil G, Trypsianis G, Kourmouli N, Livaditis M. Psychological vulnerability differences in students-carriers or not of the serotonin transporter promoter allele S: Effect of adverse experiences. Synapse. 2009 Mar; 63(3):193200.

30. Bashir R, Parveen Z, Sultana R, Khan B. A two years audit of complications of hysterectomy at Ayub Teaching Hospital Abbottabad. J Ayub Med Coll Abbottabad. 2005; 17(2):47-9. 
31. Khaskheli M, Baloch S. Abdominal hysterectomy: A common surgical procedure for benign gynaecological disease. JLUMHS. 2007 Sep; 3:94-7.
32. Dawood NS, Mahmood R, Haseeb N. Comparison of vaginal and abdominal hysterectomy: Peri-and postoperative outcome. Journal of Ayub Medical College Abbottabad. 2009 Dec 1; 21(4):116-20.

\title{
To improve is to change; to be perfect is to change often.
}

\author{
“Winston Churchill"
}

\begin{tabular}{|c|c|c|c|}
\hline \multicolumn{3}{|c|}{ AUTHORSHIP AND CONTRIBUTION DECLARATION } \\
\hline Sr. \# & Author(s) Full Name & \multicolumn{1}{|c|}{ Contribution to the paper } & Author(s) Signature \\
\hline 1 & Sarosh Khan & $\begin{array}{l}\text { Principal investigator, conceptualization and } \\
\text { design of the research work, data collection, } \\
\text { literature search, statistical analysis and } \\
\text { interpretation, drafting, revision and writing of } \\
\text { manuscript. } \\
\text { Drafting, revision and final approval, literature } \\
\text { search, statistical analysis, drafting, revision } \\
\text { and final approval. } \\
\text { Drafting, revision and final approval, literature } \\
\text { search, statistical analysis, drafting, revision } \\
\text { and final approval. } \\
\text { Drafting, revision and final approval, literature } \\
\text { search, statistical analysis, drafting, revision } \\
\text { and final approval. }\end{array}$ \\
\hline 2 & Sheema Khan & Shehla Raza Channa \\
\hline 4 & M. Adnan Bawany & \\
\hline
\end{tabular}

